\title{
ELECTROMAGNETIC LAUNCH: HIGHWAY TO THE STARS
}

Dr. Harry Fair, Carolyn Meine1, and Kelly Parks

\author{
Presented as the keynote address to the \\ Tenth International Conference \\ on Magnet Technology \\ Boston, Massachusetts \\ September $21-25,1987$
}

\author{
Publication No. PN-136 \\ Center for Electromechanics \\ The University of Texas at Austin \\ Balcones Research Center \\ EME 1.100 , Building 133 \\ Aust in, TX 78758-4497 \\ (512) $471-4496$
}


Abstract: The future of large-scale space industrialization is considered and the key role of Earth-to-space electromagnetic launch is projected. The energetic relationships of the orbits of cislunar space and trajectories are outlined so as to set the stage for understanding requirements of an Earth-tospace launcher.

Historical analogies of the progression and maturation of transportation technologies are given: Ming Dynasty vs. Portuguese and Spanish navies in 15th century; C\&O Canal vs. B\&O Railroad in 19th century.

Evidence is given that today's chemicallypropelled Earth-to-space launch is now a mature technology unlikely to yield to further major reductions in cost or increases in performance. The underlying factor behind the seemingly premature plateau in rocket technology is identified: performance in even the ultimate theoretical ideal is an exponential function of both the specific impulse of the fuel and the kinetic energy change required.

Electromagnetic launch as an alternative is examined. A point design is presented of an Earth-tospace electromagnetic launcher which approaches ideal efficiency: a superconductor quench launch of a highballistic-coefficient vehicle. Examples are calculated of how given muzzle velocities and vehicle ballistic coefficients translate into orbits and payloads attained. This design exercise identifies required enabling technologies and the research efforts now underway which may lead to desirable superconductors and vehicle structural/heat shield materials in the near future.

\section{Introduction}

For centuries, visionaries have looked to the heavens and foreseen a future in which humankind explores and builds civilizations in space and on other planets. In the fifties and sixties we enjoyed rapid progress toward this goal. The Soviet Union and the United States moved from the German V-2s of 1945 to the first artificial satellite launch, Sputnik I, on October 4, 1957, to the landing of the Eagle on the Moon July 20, 1969. The U.S. orbited the world's first space station in 1973.

But for a variety of reasons, our drive toward space has slowed. Abandoned, Skylab spiraled to its death. The Soviet Salyut space stations took their turn as workshops in orbit and now the Mir is home to space researchers. But even the Mir is smaller than the Skylab of nearly a decade and a half ago. The most striking evidence of the difficulties encountered in man's conquest of space is that today the United States does not have the ability to send anyone into space.

We are going to discuss what it is that lures us to seek to build structures and civilizations in space. In the process, we will consider past endeavors to open new frontiers. Specifically, we will consider the influence of technology in enabling mankind to explore and conquer the seas and eventually the continental interiors. And, we will explore the lessons these ventures may teach those of us who still maintain the goal of extending our civilization throughout the solar system and on to the stars.

Transportation from the Earth's surface to Earth orbit is difficult and in fact is the energy bottleneck which, in spite of progress in the last quarter century, continues to inhibit our access to space. There is strong evidence which we will detail shortly that chemically-propelled rockets are a mature technology and may be unlikely to yield the requisite major technical improvements to open the frontier of space. It may be that as in the past, entirely new technologies and new approaches are required.

We propose a radical departure from our current efforts to escape Earth's surface by using electromagnetic energy rather than chemical energy for propulsion. This idea is not new. What is new are some rather spectacular technical advances that may now provide the enabling technology to make electromagnetic Earth-to-space launch feasible. For example, developments in:

- generating intense magnetic fields

- high power density storage devices

- compact guidance and control mechanisms

- high temperature, high strength composite materials

- electromagnetic launchers

- high temperature superconductors

\section{The Future of Space Industrialization}

Let us assume for the moment that we can arrive at a practical solution to the space transportation problem and consider what, over the next quarter century, are likely opportunities for the use of space.

\section{Twenty-Four-Hour Orbits: the Hub of Cislunar Space}

The hub of space industrialization will likely occur in geosynchronous orbits and for nations at the far northern latitudes of Earth, the closely related 24-hr elliptical, highiy inclined Molniya orbits. The value of all of these is their ability to hover over a chosen geographical area of the Earth all or most of the time.

In the case of geosynchronous orbits, a satellite orbits in synchrony with the rotation of Earth to maintain a location that hovers over the equator with only minimal apparent motion from Earth. Its ground track reflects the perturbing influences of the nonspherical shape of the Earth, and the pull of the Moon and Sun by describing no more than a tight figure eight or loop each day. A satellite in a 24-hr Molniya orbit spends most of the time near apogee, which is inclined so that it may hover over a northern region.

Today, home primarily to a few communications and early warning satellites, in the next quarter century, these orbits will likely host hundreds to thousands of square kilometers of antennas and solar collectors. They may include solar power satellites, each collec- 
tor complex large as a city but gossamer as a butterfly. Each of these behemoths of the sky might beam gigawatts of power to Earthside receivers. Solar power satellites could convert the nearly continual and unfiltered sunlight of geosynchronous or 24-hr Molniya orbits into electricity for beaming via microwave or laser to Earth. The minimal gravitational stress of space would make it possible to build large solar collectors and keep them pointed at the sun using much less mass per area than possible on Earth.

Today, the USSR and Japan are studying means to build these satellites. The United States, once the leader in solar power satellite activity, has abandoned it in 1981 as problems with space transportation diverted its attention.

We may also see a global air, sea, and space traffic control network. An individual craft might tap into a network of navigation satellites to determine its location and into a data stream that could advise it of all other craft in its area, as revealed by space-borne radar and infrared sensors. Decisions could be made by a central system and communicated via satellite to advise a craft of the safest or most appropriate route.

The geosynchronous and Molniya orbits may also host communication satellites which will dwarf those of today. As space. transportation costs fall, the trend will move to placing more power and complexity in orbit, enabling transmitters and senders to shrink to pocket calculator or even wristwatch radio size.

\section{Space Assembly: Cities in Space}

How do we expect to put these vast and, in some cases, massive structures into space? Analogy to Earthside construction suggests these structures will be shipped as components and assembled on site. The driver for this approach on Earth is the trade-off between transportation and assembly costs. Items for which assembly requires expensive, specialized equipment and labor; for example, motor vehicles or refrigerators, are assembled at a centralized factory and shipped as complete units. Structures which can be more easily assembled on site are shipped as parts to save transportation costs. The overwhelming mass fraction of all construction including bridges, buildings, and even components of building are assembled on site.

Consequently, we anticipate that space stations such as the Mir, which has been designed with enough ports that it could become the nucleus of a far larger complex, will be crucial to this future scenario. The module on top will supposedly be devoted to the study of Earth resources; the one below to astrophysics. On one end, a Progress cargo ship can be docked and on the other end, the Soyuz vehicle which ferries people to and from the station. The crews of such stations will have the ability to assemble large structures, including solar power satellites and radar and communications satellites. It is space assembly that leads us to the topic of space colonies.

In the early 1970s, Professor Gerard K. O'Neill asked several of his Princeton physics classes: where is the most appropriate location for an industrial civilization? Their choice was space, not, as most people might have assumed, Earth or even the surfaces of the Moon or other planets.
There are several observations which led them to this conclusion. Space is richer in solar energy than a planetary surface: no night, no apparent motion of the sun to track, and no atmosphere for absorption. Furthermore, the lack of gravity in space enables construction of gossamer structures--perhaps shaped by Lorentz forces. Finally, space is extremely rich in mineral resources: the moons of Earth and the planets, the asteroids, and comets hold minerals in deposits that would spark a rush of prospectors if discovered on Earth.

But the work of O'Neill which has most inspired the post-Sputnik generation of space enthusiasts was his plan for space colonies.

\section{Mining the Heavens}

Recognizing the energetic efficiency of electromagnetic launch, $\mathrm{O}^{\prime} \mathrm{Ne} i 11$ proposed construction of an electromagnetic launcher, which he called a coaxial mass driver, to be placed on the lunar surface to launch ores to rendezvous with space processing plants.

In 1977, O'Nei11, Dr. Henry Kolm, and a group of Massachusetts Institute of Technology students under their supervision built a demonstration device, the Mass Driver I. This device provided the first demonstration of an electromagnetic propulsion system capable of scaling well with mass.

O'Neill proposed that his mass driver target, the L-5 libration point where the focusing effect of the interplay of the gravitational potentials of the moon, Earth, and Sun, would make capture of the payloads relatively easy.

The $L-4$ and $L-5$ points are stable: when the Sun perturbs a satellite away from one of these points, it librates about it. Because of their stability, these libration points may be the best locations for locating large space structures, such as those for processing lunar and asteroidal ores into structures, fuels, and 1 ife support supplies. The L-5 libration area inspired the name of the L-5 Society, founded in the late 70 s by Carolyn Meinel, and grew to several thousand space enthusiasts with the goal of colonizing space.

But what happened to these dreams of opening the high frontier and of space colonization? Before addressing this question, let us consider two previous examples of man's attempts to open new frontiers.

Conquering the Seas: The Ming, Portuguese, and Spanish Navies

For numerous centuries, people had sporadically sailed across thousands of miles of ocean, in the course of their adventures colonizing nearly every island on the planet. But it was not until the close of the 15th century that travel linking nearly all the coasts of our planet became routine.

Most of us are aware of the role the 15th century Portuguese Prince Henry the Navigator played in developing a sea route around the cape of Africa to the Orient, and the significant role of the Spanish-funded voyage of the Italian Columbus. But American historians rarely tell the story of the Apollo project of that century. It was the seven great Ming Dynasty voyages of exploration of 1405 through 1433, organized and captained by Cheng-Ho. 
In a century in which the European explorers risked their lives in a few tiny boats with displacements of 30 to 100 tons, the chinese set forth on voyages of expedition empowered with an entirely different approach. Their main vessels were the size of a 20 th century ocean 1 iner: approximate $7 y 140 \times 55 \mathrm{~m}$, with a displacement on the order of some 3,000 metric tons. Fleets consisted of up to 60 of these giant vessels, and included dozens of smaller support ships and even farms towed on barges. On some expeditions, fleets boasted over 30,000 sailors with individual ships carrying up to 1,000 each. Archaeologists have unearthed a rudder post over $11 \mathrm{~m}$ long from one of the Ming vessels. Using accepted chinese formulas relating rudder size to ship length, it suggests a length of between 150 and $165 \mathrm{~m}$ long.

The Ming dynasty was the undisputed scientific leader of the world at that time. They had all the technologies that undergird navigation in their hands: mechanical clocks, telescopes, the compass, meteorology. But they worked around the problem of getting lost at sea primarily through construction of their huge ships grouped into gargantuan fleets; entire cities afloat.

The Europeans took a different approach--a technological approach. The Portuguese concentrated on building a school of navigation, developed this technology to a fine art, and used this technology with much more limited resources to finally master the seas. Sea travel using, at best, only the compass and what poor maps existed at the time had conquered nearly every shore on Earth hundreds of years before. But this conquest was fitful and uncertain; sailors arrived at distant ports as much by chance as design. over a period of 60 years, Prince Henry had succeeded in revolutionizing sea travel through novel navigation techniques: sextant, clock, and detailed charts of wind and sea current to supplement the ancient mariner's compass. The Portuguese began to make consistent, methodical progress into previously uncharted realms along the coast of Africa, ultimately leading to an explosion of confidence for other explorers, colonizers, and investors to truly open the sea frontier. It was ultimately this technology which enabled the explorers and later colonists to traverse the seas with sufficient reliability to initiate a commerce and open the frontier of the new world.

\section{Conquering the Continental Interiors: the CxO vs. the BCOO}

Let us consider another example, this time from the 19th century. Remarkably, as the century had opened, little had changed in transportation since the days of the Chinese and European explorers. China had given the world the model of how to open a vast continental interior: navigable rivers, roads traveled by ox- and horse-drawn vehicles, and grand canals to link waterways wherever possible.

The United States was a young, primarily coastal nation. But her first president, George Washington, was a surveyor gripped with a dream: construction of a canal that would link the Potomac River and Chesapeake Bay with the inland, navigable Ohio River to open the interior of the new country.

However, standing in the way of his governmentchartered Patowmack Canal Company were the Appalacian mountains. For decades, progress was fitful as engineers tried to make practical use of the new technologies Washington had dreamed would make the canal construction possible. They used the new iron alloys known as steels and energetic blasting powder to demolish the gniess, shale, and limestone barriers to navigation. But the task was formidable and eventually the company gave up hope and declared bankruptcy.

The coming of the Erie Canal, which was soon to link the Hudson River to the Great Lakes of the continent's interior. frightened the merchants and politicians of the Chesapeake area. Were they to become a backwater, while the port of New York soared to national dominance?

The industrial age was dawning on: the north American seaboard, demanding coal to feed its foundries and factories. Cumberland, Maryland had coal aplenty to ship to the sleepy port of Georgetown 180 miles distant on the Potomac, if only an economical way could be found to move it. Thus, a new goal arose for the canal of which Washington had dreamed. Short of conquering the Appalacian mountains to the Ohio River, a canal to Cumberland from the Potomac would open the coal seams to foundries on the Potomac. Once the coal trade began on the canal, the profits would help it bootstrap its way across the remaining mountains to the Ohio River.

Investors and politicians met repeatedly in the U.S. capitol nearby to Georgetown and tried to gather the muscle it would take to harness modern technology for this task. The assets of the bankrupt Patowmack co. and promises of land rights were bestowed by the government on the newly formed Chesapeake \& Ohio Canal company. Juiy 4, 1828 John Adams, the President of the United States, turned the first spade of dirt at Georgetown in a race with the wealthy industrialists from New York.

A race it was, although the canal's sponsors at first failed to recognize who was their actual opponent. They thought they were racing, ultimately, to the Ohio river and the waterways of the heart of the continent, racing to get an econonic foothold before the capitalists of New York and their Erie Canal monopolized the western trade routes. But the real competitors, as it turned out, were digging their first spade of dirt that same July 4th. They were the Baltimore \& Ohio Railway and they dreamed of laying iron across the Appalacians along the same route as the planned C\&O.

Back in 1828, the United States did not yet have a single common carrier railroad. The B\&O aspired to be the first. Peter Cooper tinkered together a single cylinder locomotive engine using musket barrels as boiler tubes. Christened the Tom Thumb, Cooper demonstrated it to the management of the $B \& O$ on August 28, 1830. Suitably impressed, they selected the steam engines that soon displaced horses forever frum the roads of iron.

The adherents of the government-backed c\&O Canal barely noticed the dawning of this new age. They pressed on through the Piedmont at a good rate, reaching the first crest of the Appalacians at Point of Rocks, Virginia, named for the narrow defile where the Potomac river cuts Catoctin Ridge. It was there the first major clash occurred.

The B\&O had gotten there first. They took the only route available through the cut without blasting a tunnel. The c\&0, however, was not without friends in high places. After four years it prevailed. The 
B\&O was forced to blast a tunnel through the ridge and then resumed pursuit. At times the action got rather exciting as the two construction crews continued to vie for right-of-way and supplies, which were chronically short in that infant stage of industrialization.

The C\&O Canal reached Harper's Ferry, at the edge of the broad Shenandoah Valley, in 1833. The going was comparatively fast across that valley and the canal reached Hancock, 134 miles from its head in Georgetown in 1839. The coal banks of Cumberland were yet 50 miles distant. The most technologically challenging construction of the age of canals was yet ahead.

But the backers of the canal began to have doubts. In only three more years the rival $B \& 0$ reached cumberland. Now the financiers could see that soon the railroads would stretch across the entire continent, knitting the interior into a modern nation. Eight years after the $B \& O$ reached Cumberland, the $\mathrm{C} \& O$ straggled in. By this time, the adolescent rail industry already had nationwide approximately as many miles of iron as the canal had water.

The C\&O was never to be significantly profitable. It was the last of the great American canals, and the 8\&0 was the first of the great American railroads. One of the $B \& O$ 's engineers, George Washington Whistler, was later to build the Moscow/St. Petersburg Railroad, as yet another nation with a vast continental interior began to knit itself together.

As for the C\&0, it suffered from each of the Potomac's inconstancies as badly as the U.S. space program suffered from the shuttle challenger. A major flood could put the c\&O out of action for years on end. But the railroad could be repaired in days or, at most, weeks. One flood battered the canal in 1877; droughts shut it down for a while in 1879, and again in 1881. Finally a huge flood in 1889 forced the canal into bankruptcy. Its assets were taken over by the vastly more resilient $B \& O$.

\section{Birth, Exploitation, and Maturation of Technologies}

These are only two examples of how technology has been the key to the opening of new frontiers. First, the science and technology of navigation enabled the impoverished nation of Portugal to dominate exploration of the high seas and open the seas for continental exploration and colonization. Secondly, the new rail and steam technology beat out a governmentsubsidized canal to open trade routes and introduce civilization to the continental interior. The important questions for us today are; what are the barriers to commercial development and colonization of space? what are the critical technologies and approaches? and how can we develop them to truly open the new high frontier?

\section{The Maturation of Chemical Rocket Propulsion Technology}

A characteristic of the birth and development of any new technology is an S-shaped curve: a period of slow growth as a few pioneers test out its potential, then an explosion of rapid progress as society finds a means of using and developing the technology and finally a slowing or maturation of technology application.

It has been 4 decades since the $V-2$, thirty years after Sputnik, and 18 years since Neil Armstrong set foot on the Moon. Today, the United States is not launching anyone to space. The dream of space colonization in the $80 \mathrm{~s}$ is shattered. Is this a consequence of technology or national will? Have we reached the plateau of chemical rocket propulsion technology? or have we lost interest in space?

The Paris Air Show held last June was bursting with hardware indicating the world's continuing intense interest in utilizing space. The People's Republic of China, France, India, as well as the Soviet Union and the United States all have plans for the future and they all hinge on chemical propulsion technology.

Recently, James Bennett of the American Rocket Company and economist Phillip Salin have attempted to chart the economic progress of chemical rocket launch technology.[1] This is not an easy task, since all the launches were performed by governinent-owned rockets and, consequently, the figures they give for launch costs are difficult to unravel. For example, experts have at times differed by over an order of magnitude on the real cost of a shuttle launch: was it to be $\$ 200 / 1 b$, as NASA indicated, or $\$ 6,820 / 1 b$, as Greg Easterbrook calculated in Newsweek?[2]

In a study just released by Columbia University Press, [3] John and Ruth Lewis indicate that launch costs have stagnated. Taking estimated costs for U.S. launch systems which are regarded as fairly reliable, they conclude that we have made no significant progress in reducing launch costs since the Saturn I three decades ago. They contrast this with projected costs: with each new chemically-propelled launch system, dramatic savings were predicted. But as each system was developed, the costs essentially refused to budge.

The major deterrent to the development and utilization of space resources appears to be the relatively high cost of transportation to earth orbit. Is there an alternative technology that offers a solution?

\section{Electromagnetic Launch}

We have already mentioned in passing the coaxial mass driver of Gerard $\mathrm{O}^{\prime} \mathrm{Ne} i \mathrm{ll}$ and Henry Kolm. At about the same time, as director of the Army's Propulsion Laboratory along with Drs. Peter Kemmey and Thaddeus Gora, we were faced with the challenge of achieving higher and higher velocities for various propulsion applications. We independently came to the same conclusion as $0^{\prime} \mathrm{Ne} i l 1$ and Kolm. In order to break the bonds of velocity in a cost-efficient manner, we must at least evaluate electromagnetic propulsion as an alternative to chemically propelled guns and rockets.

Meanwhile, Richard Marshall and co-workers at the Australian National University in Canberra, working independently of $0^{\prime} \mathrm{Ne} i 11$ and my group, were developing unique solid metal brushes to withstand extremely high pulsed current densities with a goal of accelerating small masses to extremely high velocities to achieve impact fusion. Using the world's largest homopolar generator (HPG)(550 MJ) to power a $5 \mathrm{~m}$ long electromagnetic railgun, Marshall's group accelerated intact a $3 \mathrm{-g}$ plastic projectile to $5.9 \mathrm{~km} / \mathrm{s}$. This was an important record and demonstrated the feasibility of railgun accelerators to launch materials to hypervelocities.

These three groups were hardly the first to think of electromagnetic launch. It had been explored by 
the Japanese and Germans during World War II, and an advertisement dating back to 1844 promised an exhibition of Colone1 Dixon's "newly invented electric gun."

But just as navigation technology had to await the development of astronomy and the clockmaker's art; just as the railroad had to await the invention of harder iron alloys and the refinement of machinists' arts, so had electromagnetic propulsion been awaiting the development of its supporting technologies.

The basic difference between the rail launcher of Marshall's and the coil launcher of O'Neill's was that the rail device uses a conductive armature across a pair of rails to accelerate the projectile, while the coil device uses the attracting and repelling magnetic fields of a set of launcher coils to act on magnetic fields within the projectile or its cradling sabot. For velocities needed for Earth-to-space launch, these launchers must operate at velocities and conditions not experienced in conventional guns or missile systems.

Let me quickly summarize the progress and technology to date.

In 1978, I was invited to present the concept of electromagnetic launch to the Technology Trends Colloquium, a meeting organized by the office of the Secretary of Defense (OSD) to explore new or emerging technologies and their applications. As a result of this conference, I was asked to form a National Advisory Panel that included Henry Kolm of MIT, Peter Mark of Princeton University, James Powell of Brookhaven National Laboratory, William Weldon of The University of Texas at Austin, Richard Marshall of the Australian National Laboratory, Philip Thullen of Los Alamos National Laboratory, and two Army Propulsion Laboratory physicists Peter Kemmey and Thaddeus Gora.

At the panel's initial meeting at the National Magnet Laboratory (MIT), we outlined a plan to capitalize on recent advances in pulsed power arising from the emphasis on directed energy weapons research and fusion research. We conciuded that advances in the development of critical components over the previous decade would now permit the development of practical electromagnetic guns and launchers. We subsequently organized a December 1978 technical workshop at the U.S. Naval Academy in Annapolis, MD, to discuss the advances in component technologies and possible applications. These included orbit-to-orbit space transportation, Earth-to-space and Moon-to-space launch, impact fusion, equation-of-state research, and electromagnetic guns for national defense.

Research moved forward quickly. In 1980, the Army sponsored the First Conference on Electromagnetic Guns and launchers at San Diego. Focusing on basic technology, the meeting highlighted the Center for Electromechanics at The University of Texas at Austin's (CEM-UT's) 5-MJ HPG, railgun experiments using explosive magnetocumulative generators at Los Alamos National Laboratory, a proposal to use rotating-bed nuclear reactors for power in space, the construction of the Westinghouse developed EMACK railgun at the Army Armament Research and Development Command, and analyses of space propulsion and impact fusion.

Subsequent developments were fast paced, often exceeding expectations. The Defense Advanced Research Projects Agency (DARPA) became the major sponsor for university and industry research efforts. At the
DARPA sponsored Second Electromagnetic Launch Symposium in Boston in October 1983, attendees were presented the initial tests of the EMACK railgun which accelerated a $300-\mathrm{g}$ projectile to $4.2 \mathrm{~km} / \mathrm{s}$. The Center for Electromechanics reported that its compact 5-MJ homopolar generator had achieved 1 MA currents (vs. a goal of $0.75 \mathrm{MA}$ ). Meanwhile, The University of Texas had begun to extend its homopolar generator activity from commercial welding and other pulsed-duty industrial operations to railguns. The first railgun by the Center for Electromechanics was developed in 1979. It was quickly followed by more advanced designs for powering Earth-to-space launchers and hypervelocity impact experiments.

The major focus of activity in this field during the past five years has been the development of power sources and electromagnetic launchers for national defense. Much of this work has been directed by DARPA and the Army and, more recently, by these organizations and the Strategic Defense Initiative Organization (SDIO) and the Air Force. Major success has been achieved in reducing the size of the necessary power sources and power conditioning equipment. The energy density of capacitors has been increased by an order of magnitude by Maxwe 11 Laboratories and The University of Texas has increased the energy density of homopolar generators by factors of 20 or more. The University has 1 icensed the manufacture of their homopolar generator technology to Parker Kinetic Designs so these power sources are available commercially. A major contribution to the technology was the design and construction of a $60 \mathrm{MJ}$ homopolar generator system, funded entirely by The University of Texas System. The University has also demonstrated the first repetitive power source coupled to an electromagnetic launcher by demonstrating a compensated pulsed alternator (compulsator) powering a railgun system which has fired a burst of projectiles at a rate of 60 per second.

In 1985, DARPA and the Army initiated a major technology demonstration program. The goals were to build several laboratory launchers which were to provide the next order in magnitude of projectile kinetic energy. Two laboratory launchers are nearing completion; a railgun powered by capacitor banks is being constructed by Maxwell Laboratories and a railgun powered by the $60 \mathrm{MJ}$ homopolar generator system has been constructed by The University of Texas. Both laboratory guns will be capable of accelerating large projectiles to 2 to $4 \mathrm{~km} / \mathrm{s}$ with $9 \mathrm{MJ}$ of kinetic energy in the projectiles. Several concurrent programs are developing projectiles to withstand the high accelerations required for launch from these laboratory guns and to withstand the hostile aerodynamic and aerothermal environment resulting from the atmosphere at these velocities. To address this problem, the technology developed for reentry vehicles is being scaled down to projectiles for testing in the 9-MJ launchers. Both of the 9-MJ launchers will become sperational before the end of 1987 and will be utilized for investigation of the physics of hypervelocity impact and the development of advanced launcher components. Until very recently, light gas guns, which used hydrogen gas to drive small projectiles to velocities of up to 10 $\mathrm{km} / \mathrm{s}$, had been the only means short of a full sounding rocket launch to achieve hypervelocities for this type of experimentation.

The DARPA/Army program is also developing an additional generation of laboratory guns which will be located at a large test range to obtain information for developing hypervelocity projectiles capable of 
surviving a substantial flight through the atmosphere. Three different systems are under construction; a capacitor-driven railgun by Maxwell Laboratories and the FMC Corporation, a compulsator-powered railgun by The University of Texas, and a coilgun driven by a new type of generator by the Kaman corporation. This collgun is the most aggressive current attempt to demonstrate a nonrail launcher. All of these launchers will be capable of launching large projectiles to 2 to $4 \mathrm{~km} / \mathrm{s}$ with $9 \mathrm{MJ}$ projectile kinetic energy but with the additional features that they will be capable of repetitive operation at several launches per minute and will be located at an appropriate facility for the demonstration and development of atmospheric projectiles.

Concurrentiy, other activities have demonstrated the acceleration of small (gram-size) projectiles to extremely high velocities with several laboratories reporting to 6 to $10 \mathrm{~km} / \mathrm{s}$. Most of the activity in developing this technology is summarized in the proceedings of the biennial Symposia on Electromagnetic Launch Technology. $[4,5,6]$

\section{Superconductors and the}

Quench Launcher Concept

Although the progress in electromagnetic propulsion has been spectacular in the past several years, numerous problems remain to be solved before one can hope to demonstrate the launch of significant mass to earth escape velocities.

The availability of superconductors as practical engineering materials will have enormous impact on every aspect of the electromagnetic launchers' system. The higher temperature superconductors will drastically alter the types of systems used and the difficulties encountered. Power supplies are the most obvious--superconducting storage inductors and rotating machines have been developed in the past, but they will be greatly simplified as the higher transition temperature materials becone practical. Electromagnetic launcher structures will benefit in simplicity, size, weight, and efficiency. The reduction in Joule heating will virtually eliminate some thermal management components and the improvement in efficiency will result in significantly smaller prime power and pulse conditioning components and systems.
But the most important effect of these materials is that they will enable an entirely new class of electromagnetic launchers. These launchers generally have some or all of the following in common: 1) the use of slowly-charged electromagnetic structures in the launcher as part of the power compression chain; 2) the use of energy-conserved persistent-current coils to provide excitation fields; 3 ) induction-fed armatures in which currents must persist without decay during the launcher; and 4) commutation and current switching using superconductive/normal transitions.

The most promising of these new launchers for Earth-to-orbit application is the solenoid Quench Gun, a superconducting solenoid launcher depicted in figure 1.

A discrete coil configuration of this launcher was proposed by Henry Kolm some nine years ago. $[7,8,9]$ The principle is simple. A solenoid structure tends to increase its inductance by shrinking along the axis. The armature or projectile coil is attracted into the solenoid and, in the process, commutates current out of the nearest stator coil. If that coil can be perturbed to make a superconducting to normal transition, then the process of acceleration continues with a direct conversion of magnetic to kinetic energy. The configuration is simple, potentially very efficient, and easily permits levitation of the projectile to avoid mechanical contact with the barre1.[10]

The quench gun is elegantly simple in contrast to alternative electromagnetic launch schemes which have been considered in the past (fig. 2). All of the critical power storage and conditioning functions are performed by the superconducting material.

General Considerations of scale: To make practical, useful launchers, some broad measures of scale are needed. Guns and launchers, to be practical, must operate at high mechanical stresses. With common engineering material, this implies magnetic pressures of 2 to 4 kbars. This means that magnetic fields of about 20 Tesla to 30 Tesla are needed. High permeability ferromagnetic circuits or permanent magnets are restricted to $1 / 10$ of the required fields (or about $1 / 100$ th of the required pressure) and are not generally of use for these devices. To provide the

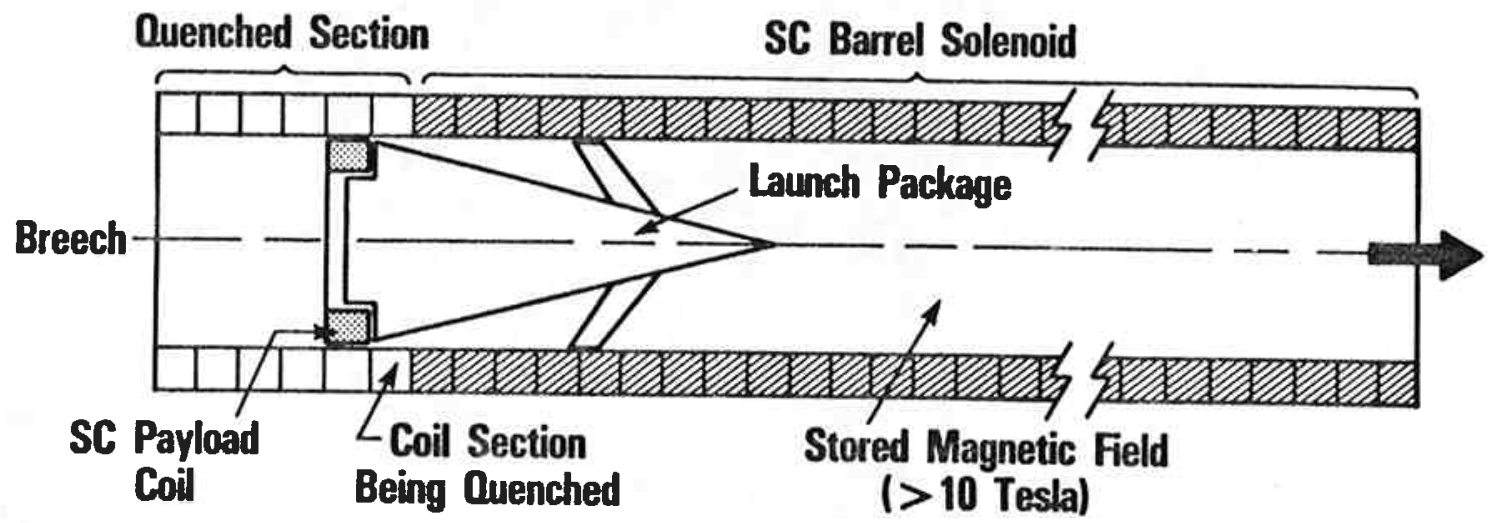

Figure 1. Solenoid quench gun 

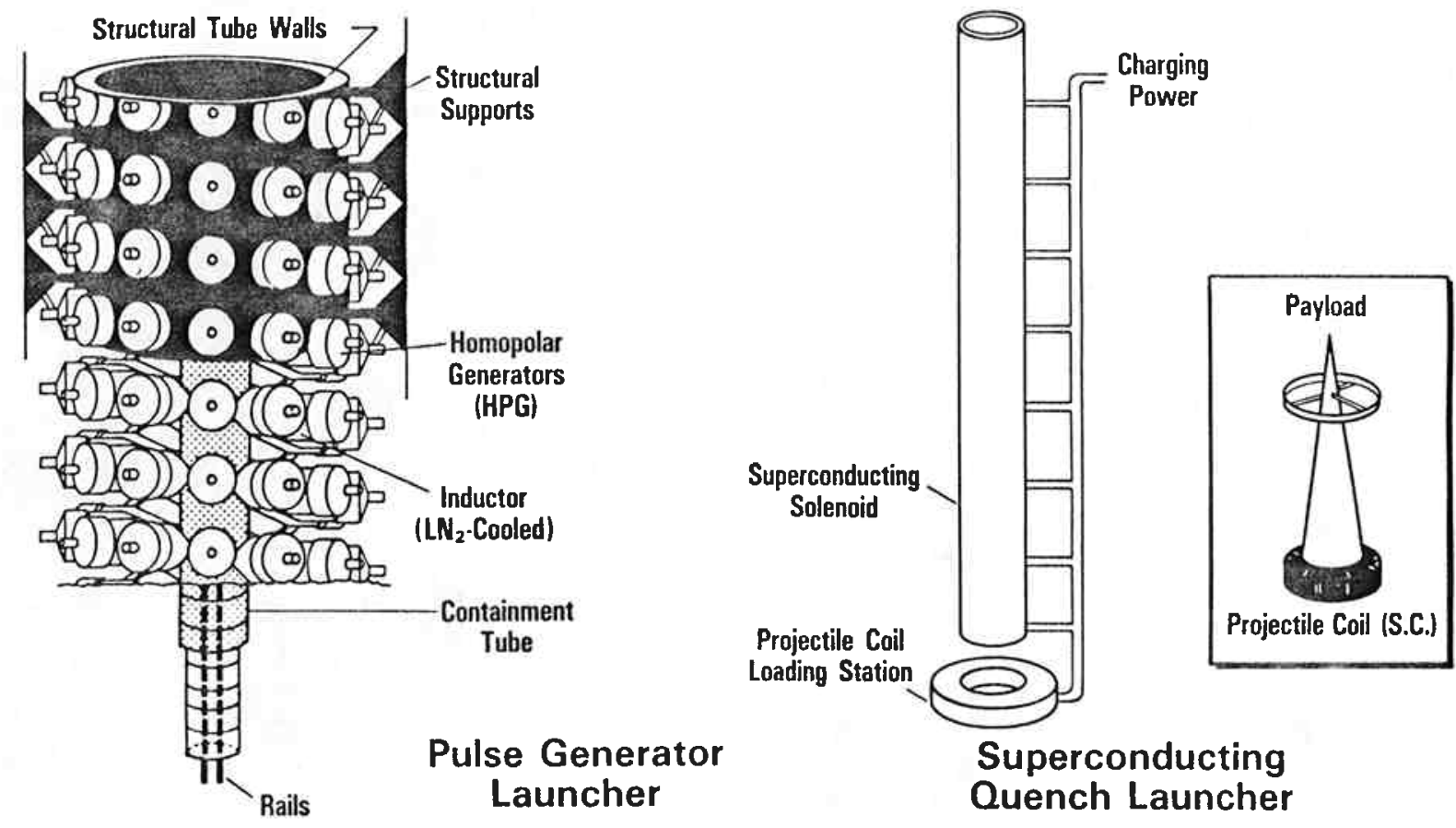

Figure 2. Alternative electromagnetic launch schemes

magnetic fields, the magnetization is generally on the order of millions of ampere-turns. Monolithic structures made from warm superconducting materials and containing persistent currents may represent the future "permanent magnets."

Paxload Sizing Issues: For reasons of cost and reliability, it is obviously important to evaluate the stress limits on the materials required for the launcher and payload. But there are other considerations for the payload size which may indicate advantages to larger numbers of launches with payloads much smaller than available in the shuttle or Energiya.

Recently, James Bennet of the American Rocket Company and economist Phillip Salin have attempted to chart the economic progress of chemical rocket launch technology. The shuttle was planned to fly a maximum of 48 flights/year, with only 5 vehicles built: Presuming what is still an incredibly high rate of 20 launches/year, the learning curve rate is 3\%. By contrast, the same study estimates that the Delta II, if it were to be rolled off the production at the rate needed to match the payload delivery of 20 shuttle flights, would show a respectable 15\%/year learning curve rate.

A study performed at MIT in 1977 estimated that a payload size even smaller than the Delta's, at 1 ton, would maximize the trade-off between learning curve and the economy of scale of larger payloads. Thus, initially, it may be useful to consider a 1 ton payload for the superconducting quench gun and evaluate the effects on the critical components and scale.

Launch: The coils of the launcher solenoid would be charged to provide a field on the order of 20 to 30 $T$. The sabot would contain a superconducting coil which would be attracted by the solenoid. A fluxcompressive shape on the sabot, perhaps a finger- shaped object leading it, would force each coil in the bore to quench just before the magnet coil of the sabot would pass. As the sabot reaches the mouth of the bore, the entire solenoid would have been quenched. Efficiency of conversion of electrical-tokinetic energy of the sabot plus projectile would be nearly $100 \%$ if the quenched current has been shunted to another superconducting circuit.

Chemical rockets for space payloads are launched from sea level in part because of the large size of the rocket propulsion systems and the difficulty of transporting them from the place of manufacture to the place of launch. But, for delivery of 1 ton to orbit, the entire quench launcher sabot/projectile combination will weigh on the order of tens of tons. As a consequence, many high altitude mountain peaks and plateaus would be readily accessible as the launch site. For launch into geosynchronous orbit, a nearequatorial location would minimize the plane change required for orbit insertion. Fortunately, there are numerous peaks in the Hawaijan Islands, other parts of the United States, the Ecuadorian and Peruvian Andes, Kenya, and Indonesia which are excellent candidates for launch to geosynchronous orbit.

Surprisingly, with an exit velocity of nearly 11 $\mathrm{km} / \mathrm{s}$, very little velocity is expected to be lost during atmospheric transit. Above $8 \mathrm{~km} / \mathrm{s}$ velocity, theory predicts the projectile will remain in a laminar flow regime. Consequently drag will be negligible, with a drag coefficient on the order of 10-5. For example, when the re-entering space shuttle is in this regime, it experiences very little drag.

The ability to create drag could be an advantage if it is desired to use an aerodynamic maneuver to convert vertical velocity to horizontal in the high atmosphere. Such a maneuver would cut the on-board rocket propellant needed to insert a payload into final orbit. Test vehicles such as the Sandia Winged Energetic Reentry Vehicle have shown such high alti- 
tude maneuvers are feasible, but only at far lower velocities where turbulence may dominate drag effects. Thus, initially, a quench launcher would likely launch the projectile on a near-ballistic trajectory through the atmosphere.

Although we expect little drag on the vehicle, calculations of shock heating estimate temperatures as high as $7,000 \mathrm{~K}$. The tip of the projectile will be approaching the $7,000 \mathrm{~K}$ shock wave temperature. Previous studies on Earth-to-space electromagnetic launch have differed widely on what materials are most appropriate, ranging from stainless steel to carbon/carbon weave. Most of this heat transfer occurs though radiative heating, which is rather inefficient and of seconds duration; a nearly vertical launch will take only a second or two to escape most of the atmosphere from an elevated location.

We know from meteorites which have arrived at the Earth's surface that tolerating enough ablation, almost any material can punch through the atmosphere. The quench launcher's projectiles must do it in reverse, with the highest pressure and heating occurring at muzzle exit. There is no experimental evidence of what the behavior is of projectiles at 8 $\mathrm{km} / \mathrm{s}$ and higher in the atmosphere at $4-\mathrm{km}$ altitude. While it may be easier to have the highest heating and shock wave pressure come first when the projectile is cold, we have no experimental evidence to support this.

Orbit Insertion: For insertion into geosynchronous orbit, the vehicle would be required to make a slightly less than $2 \mathrm{~km} / \mathrm{s}$ change in velocity with a fast burn of its on-board solid fuel rocket near apogee. Taking a typical value for the specific impulse of $380 \mathrm{~s}$, fuel equal to $50 \%$ of the vehicle mass will be required for geosynchronous orbit insertion. Engine structure and navigation and control components could add another $10 \%$.

With this staging of the vehicle, the launcher would deliver 1 ton of payload to geosynchronous orbit using 1.5 tons of rocket and fue 1 and 0.5 ton for heat shield, gee load structure, and sabot combined for a total launch mass of 3 tons.

\section{The Economics of Space Launch}

The cost of putting a pound of anything in space is dominated more by the technological approach than by any cost cutting, high-intensity management of the aerospace industry. Recent discussion has focused on the United States' decision in the late 1960s to develop the space shuttle as opposed to using largebooster rockets to launch all major U.S. payloads to space. Determining the actual cost of launching a pound of material to space is perhaps even more challenging and certainly less reliable than merely launching a vehicle to space. The estimates for the Shuttle range from approximately $\$ 300 / 1 \mathrm{~b}$ to orbit by NASA to $\$ 2,000 / 1 b$ by NASA's critics. The cost for all launch systems generally seems to fall in the several thousand per pound range and may be driven by the physics of the chemical rocket launch technology. All chemical rocket space launch systems are, unfortunately, subject to the same limitations determined by the rocket equation. The shuttle and systems using big booster rockets all have, at most, about 18 of the total weight of the launch vehicle as payload. All of this mass must be accelerated and expendable mass (99\% of the total weight) contributes significantly to the total cost.
Alternatively, in the example of the electromagnetic quench launcher described here, the ratio of payload to total launch vehicle mass is $1: 3$. The cost of the electromagnetic launcher which must be amortized over the number and frequency of launches will largely determine the final cost per pound, but it is unlikely to be as high as even the most optimistic estimates for any of the chemical rocket systems.

\section{Sumary}

Dreams of pursuing the high frontier of commercial ventures in space and space colonies have been shattered by the stagnating cost of launching material to space. Historical analogies demonstrate that the science and technology of navigation in the 15 th century and the technological revolution created by the exploitation of steam power and the railroads in the 19 th century were required to break the stagnation and open the frontiers of the new world and the continental interior. Chemical rockets for launching material to space represent a mature technology and have defeated all attempts to substantially reduce launch costs. As in the historical analogs, opening the high frontier may require a complete revolution in the means of launching material to space. Electromagnetic rather than chemical energy is proposed as an efficient, cheap, and practical alternative. Recent advances in several critical technologies now indicate that small scale launchers could be built immediately to demonstrate the feasibility of launching material to space. Full scale launchers should await the successful feasibility demonstration but hold the near-term promise for a revolution in launch to space.

\section{Acknowledgements}

We wish to thank Ors. Peter J. Kemmey and Henry Kolm for their helpful discussions on superconductivity and the quench gun.

\section{References}

[1] J. Bennett and P. Salin, "Privitizing Space Transportation," Issue paper, Reason Foundaton, Santa Monica, California, 1987.

[2] G. Easterbrook, "Big Dumb Rockets," Newsweek, pp 46. August 17, 1987.

[3] J. S. Lewis and R. A. Lewis, Space Resources: Breaking the Bonds of Earth, Columbia University Press, New York, 1987.

[4] 1980 Conference of Electromagnetic Guns and Launchers, IEEE Transactions on Magnetics, vol. 18, no. 1, January 1982.

[5] 2nd Symposium on Electromagnetic Launch Technology, IEEE Transactions on Magnetics, vol. 20, no. 2, March 1984 .

[6] 3rd Symposium on Electromagnetic Launch Technology, IEEE Transactions on Magnetics, vol. 22, no. 6, November 1986

[7] H. Fair, P. Kemmey, and T. Gora, "First Meeting of the Advisory Panel on Electromagnetic Guns and Launchers," Propulsion Technology Laboratory Report no. 08-104-78.

[8] H. Kolm, P. Mongeau, and F. Williams, Electromagnetic Launchers, Intermag-80, Boston, March 1980

[9] H. Kolm and P. Mongeau, "An Alternative Launching Medium," IEEE Spectrum, April 1982, pp. 30 .

[10] T. Gora and P. Kemmey, "Fast Electromagnetic Launchers," IEEE Transactions on Magnetics, vol 19 , no. 4, 1983. 